\title{
DESAFÍOS \\ DE LA INTERAMERICANIZACIÓN \\ DEL DERECHO: LA CONTRIBUCIÓN \\ DEL IUS CONSTITUTIONALE COMMUNE
}

LEONARDO GARCÍA JARAMILLO 
SUMARIO

INTRODUCCIÓN. I. LA INTERAMERICANIZACIÓN COMO EPIFENÓMENO DE LA GLOBALIZACIÓN DEL DERECHO. II. REALIDADES FÁCTICAS Y JURÍDICAS AFINES QUE REFUERZAN EL COMPARATIVISMO. III. EL IUS CONSTITUTIONALE COMMUNE Y LA INTERAMERICANIZACIÓN DEL DERECHO. IV. LOS CÁNONES EN EL DERECHO CONSTITUCIONAL: CUÁLES SON Y CÓMO TRANSFORMARLOS. V. A MANERA DE CONCLUSIÓN. REFERENCIAS. 


\title{
DESAFÍOS \\ DE LA INTERAMERICANIZACIÓN DEL DERECHO: LA CONTRIBUCIÓN DEL IUS CONSTITUTIONALE COMMUNE
}

\author{
LEONARDO GARCÍA JARAMILLO
}

\section{INTRODUCCIÓN}

Las comprensiones dominantes de la «globalización» han distinguido fundamentalmente tres campos donde acontece: la economía, la cultura y la política ${ }^{3}$. Si bien entre sus especialistas no hay una definición ampliamente aceptada del concepto, conviene aportar algunas precisiones preliminares que orienten nuestro

${ }^{1}$ Leonardo García Jaramillo. Universidad EAFIT-Medellín. Carrera 49, n. 7 Sur-50. Bloque 38, oficina 322. Medellín, COLOMBIA. M. A. con énfasis en estudios políticos, Universidad EAFIT-Medellín. M. A., Università di Genova, Italia. Profesor, Departamento de Gobierno y Ciencias Políticas, Universidad EAFIT-Medellín. Editor de Co-herencia. Revista de Humanidades. Columnista de Ámbito Jurídico. Ha publicado artículos y traducciones en revistas especializadas. Autor de Constitucionalismo deliberativo. Estudio sobre el ideal deliberativo de la democracia y la dogmática constitucional del procedimiento parlamentario (México: UNAM-IIJ, 2015).Email: lgarciaj@eafit.edu.co

${ }^{2}$ Este artículo presenta resultados de la investigación «Activismo judicial y dogmática de márgenes de acción: el caso colombiano», presentada como tesis de maestría en la Università di Genova, Italia. Agradezco a mis directores: Pierluigi Chiassoni y Susanna Pozzolo por sus observaciones. Una versión posterior se impartió en «El constitucionalismo transformador en América Latina: Desafíos del Ius Constitutionale Commune a la luz del diálogo con el espacio común europeo y el derecho económico internacional». Cátedra Europa, Barranquilla-Colombia, marzo de 2016. Agradezco a Mariela Morales, Silvia Gloria de Vivo y Yira Segrera la oportunidad de participar en la Cátedra, así como a Viridiana Molinares, Magdalena Correa, René Urueña, Manuel Góngora y Franz Ebert por el diálogo crítico.

${ }^{3}$ En el derecho se habló durante más tiempo de su internacionalización. Véase, Jan Sieckmann-Laura Clérico (eds.) Internacionalización del Derecho Constitucional. Constitucionalización del Derecho Internacional, Buenos Aires: Fundación Alexander von Humboldt-EUDEBA, 2012. 
análisis. De manera sucinta podría entenderse como el proceso mediante el cual diversos tipos de innovaciones tecnológicas, económicas, políticas y jurídicas, han reducido radicalmente las barreras tradicionales de intercambios entre países. Las fronteras de los estados-nación están exhibiendo mayores fracturas por donde permean flujos trasnacionales de bienes, servicios, capital, personas, ideas, cultura, tecnología y conocimiento. Estos intercambios se han transformado en su intensidad (entre países desarrollados) y en su naturaleza (entre los países desarrollados y los subdesarrollados, así como entre éstos exclusivamente).

El concepto «globalización» provoca, a lo ancho del espectro político, la sensación de que la acción en gran medida incoordinada por parte de actores que muchas veces no pueden identificarse plenamente, está transformando la vida política, social y económica de formas que aún estamos por comprender y que está más allá de nuestro alcance impedir ${ }^{4}$. Los gobiernos no solo reducen las barreras del intercambio transnacional, sino que su capacidad para imponerlas y protegerlas se aminora ${ }^{5}$. Se propicia entonces una diversificación y una expansión de la escala donde el poder se ejerce y se jerarquiza ${ }^{6}$.

Held caracteriza la globalización a partir de: (1) el grado de extensión, es decir, el amplio rango que han alcanzado ciertas actividades a través de fronteras y largas distancias; (2) la intensidad o la magnitud de la interconectividad inherente en estas operaciones; (3) la «velocidad», que se pregunta cómo estas operaciones han ganado en velocidad, por ejemplo, en las comunicaciones. Denomina al último factor (4) «confusión» entre lo global y lo local, en la medida en que acontecimientos locales tienen cada vez más consecuencias globales ${ }^{7}$. Desarrollos globales se materializan cada vez más localmente aunque con considerables variaciones, como sucede con las normas y las instituciones jurídicas ${ }^{8}$.

El último factor se refleja sobre todo en el derecho debido a las fronteras cada vez más difusas entre el derecho local y los derechos internacional y de otros

${ }^{4}$ David S. LAw, «Globalization and the future of Constitutional Rights», en: Northwestern University Law Review, Vol. 102, n. ${ }^{\circ}$ 3, 2008.

5 Ibidem.

${ }^{6}$ Daniel W. Drezner, «Globalization and Policy Convergence», en: International Studies Review. Vol. 3, No. 1, 2001. David Held - Anthony McGrew (eds.), The Global Transformations Reader: An Introduction to the Globalization Debate. Cambridge, Polity, 2003, Introduction. Para una reconstrucción de las distintas dimensiones de la globalización: Manfred B. Steger, Globalization: A Very Short Introduction. Oxford University Press, 2003.

7 David Held - Anthony G. McGrew, et al., Global Transformations: Politics, Economics, and Culture. Stanford, Stanford University Press, 1999.

${ }^{8}$ En su evaluación acerca de cómo en distintos períodos históricos han operado los procesos de globalización, Held analiza la globalización en: la organización política, lo militar, el comercio, las finanzas, la productividad corporativa, la migración, la cultura y el ambiente. Ibidem. 
países ${ }^{9}$. Los procesos de globalización sin duda transforman el derecho y, en particular, el derecho constitucional por el conjunto de características afines del nuevo constitucionalismo latinoamericano que promovieron por su aplicación la necesidad de intensificar el diálogo. Tales características del ius commune latinoamericano se destacan más adelante.

La globalización del derecho, reforzada por la globalización en otros ámbitos, ha ejercido influencia sobre la configuración paulatina de regímenes constitucionales, es decir, del conjunto de instituciones razonablemente estables a través de la cuales se toman las decisiones fundamentales de la nación y los principios que orientan tales decisiones ${ }^{10}$. La globalización del derecho, que ha creado e intensificado patrones particulares de desarrollo para el derecho constitucional, es un fenómeno incuestionable e irreversible. Es una verdad evidente sobre todo en el derecho constitucional latinoamericano donde, más que en cualquiera otra región del mundo (incluso Europa con su Tribunal de Derechos Humanos), puede hablarse con propiedad de la internacionalización del derecho constitucional. Esto se debe sobre todo a las afinidades orgánicas (creación de tribunales constitucionales independientes) y dogmáticas (principios y derechos consagrados de forma similar como disposiciones constitucionales) en los procesos de reforma acometidos en la región, aunadas a los instrumentos del Sistema Interamericano de Derechos Humanos. En la interpretación y concreción de disposiciones constitucionales propias, o del derecho internacional o extranjero, los tribunales han contribuido a crear una doctrina constitucional genérica en la región, que se distancia de la exégesis divulgativa de doctrinas transnacionales.

En la región se ha venido extendiendo y consolidando un «derecho constitucional genérico» ${ }^{11}$, es decir, un cuerpo de teoría, metodología y doctrina constitucionales que no pertenece exclusivamente a ninguna jurisdicción. Es afín en normas, principios, instituciones judiciales y teorías que han adquirido particular relevancia en la creación y desarrollo locales del derecho, así como en las agendas locales de investigación. En la construcción de este derecho constitucional genérico se destacan países como México, Costa Rica, Colombia, Perú, Ecuador, Bolivia y Argentina, donde su doctrina, jurisprudencia y derecho legislado han estado particularmente abiertos al influjo creativo de cánones trasnacionales.

9 Una de las principales exposiciones sobre la globalización del derecho es, William Twining, General Jurisprudence. Understanding Law from a Global Perspective. Cambridge University Press, 2009. Para una síntesis de algunos puntos fundamentales, véase su contribución («The Implications of Globalisation for Law as a Discipline») a: Andrew Halpin - Volker Roeben (eds.) Theorising the Global Legal Order. Oxford: Hart, 2009.

10 Mark Tushnet, The New Constitutional Order. Princeton University Press, 2003.

11 David Law, «Generic Constitutional Law», en: 89 Minnesota Law Review 652, 2005. 
Las reglas, principios, instituciones judiciales y teorías, a pesar de haber surgido dentro de prácticas jurídicas y contextuales particulares, configuran un canon a medida que viajan y son receptadas creativamente en otros países para responder a nuevos desafíos de cara a la pobreza, la desigualdad, el híper presidencialismo y los problemas de representación política deficitaria. Los países reciben elementos del canon y, a medida que encuentran nuevas formas de concebirlos, interpretarlos y aplicarlos, contribuyen en el desarrollo de sub-cánones o cánones latinoamericanos $^{12}$. Experiencias locales relativas a la implementación de normas o doctrinas, hacen parte del diálogo regional para no repetir hechos desafortunados del pasado y para aprender de otras experiencias en la solución de nuestros problemas más acuciantes.

En contextos afines signados, de un lado, por la pobreza, la desigualdad y los déficit en la representación política, y de otro, por la proclamación de constituciones con vocación normativa, un amplio catálogo de derechos, mecanismos judiciales para propender por su garantía y un tribunal independiente encargado de proteger y desarrollar estas provisiones, se comprende porqué la academia jurídica y los tribunales nacionales, así como la Corte Interamericana de Derechos Humanos, han llegado a compartir intereses teóricos, métodos y doctrinas que propician el desarrollo de una doctrina constitucional genérica latinoamericana. Esta doctrina se consolida en un proceso que, siguiendo teorizaciones

${ }^{12}$ La creación del principio de proporcionalidad en el antiguo derecho de policía prusiano, su configuración en el derecho alemán tras la Ley Fundamental de Bonn de 1949 y su viaje a América Latina, donde fue a su vez reconfigurado doctrinaria y jurisprudencialmente, constituye un ejemplo para explicar este fenómeno de configuración colectiva de un canon a partir de los países receptores, del sur global. Por ejemplo, en su formulación procedente de la dogmática alemana, el principio se descompone en tres subprincipios. El primero (idoneidad) verifica que la medida examinada persiga un fin legítimo y que contribuya de modo efectivo a su consecución. En la forma como se empezó a implementar, el juicio acerca de la legitimidad del fin se separó del examen de idoneidad. La separación del examen del fin de la norma del contenido del subprincipio de idoneidad, se consideró adecuada debido a que son diversos el tipo de argumentos y los problemas que plantea el examen de la legitimidad del fin y de la idoneidad del medio. En el caso de la Corte Constitucional Colombiana (C-916/02), a pesar de que la proporcionalidad se definió como «una directiva no explícitamente positivizada en la Carta Política», se ha ofrecido una fundamentación constitucional indirecta de dicha herramienta argumentativa (C-226/02 y C-822/05). El principio se dedujo jurisprudencialmente de la concepción de Estado social de derecho y del principio de dignidad humana (art. 1), del principio de efectividad de los principios, derechos y deberes (art. 2), del reconocimiento del carácter inalienable de los derechos (art. 5), del establecimiento de la responsabilidad de las autoridades por extralimitación de las funciones públicas (art. 6) y del artículo 214 que establece el requisito de proporcionalidad de las medidas adoptadas durante los estados de excepción. 
sugestivas, podríamos denominar «interamericanización» ${ }^{13}$. Se trata de un proceso mediante el cual se crean y configuran en América Latina cánones propios a partir de elementos de los cánones trasnacionales, pero luego de procesos de reconfiguraciones y resignificaciones.

Este trabajo analiza algunas particularidades del proceso de globalización del derecho en el contexto latinoamericano por cuyas especificidades resulta útil el concepto «interamericanización» desarrollado al interior del proyecto del Ius Constitutionale Commune en América Latina (ICCAL): la concepción que mayor potencial tiene en la región actualmente para comprender la interamericanización del derecho y analizar una de sus características más desafiantes, como es la posibilidad de transformación social desde el constitucionalismo.

Si bien los países de la región han tenido históricamente, al crear e interpretar derecho, fronteras fracturadas y relativas, desde hace algunas décadas se ha venido modificando la forma como acontecía el diálogo y la interacción entre países, fundamentalmente, exportadores de reglas, principios y ciencia jurídica (el llamado norte global) y países receptores (el llamado sur global). En la actualidad la interacción se ha vuelto también horizontal entre los países del sur global que, a partir de elementos teóricos y judiciales de los cánones creados en el norte global, han construido un diálogo propio. Los procesos de interamericanización del derecho han alterado la conformación y el desarrollo de las redes tradicionales de interdependencia en la creación de normas e instituciones.

\section{LA INTERAMERICANIZACIÓN COMO EPIFENÓMENO DE LA GLOBALIZACIÓN DEL DERECHO}

La globalización del derecho ha tenido varias consecuencias, algunas de las principales ya destacadas, así como varios epifenómenos —es decir, uno de varios fenómenos que se dan después de otro considerado principal- dentro de los cuales se destaca el proceso de la interamericanización del derecho. Aunque se han dado algunas experiencias de diálogo e intercambios entre académicas y poderes judiciales latinoamericanos con sus pares en la India y Sudáfrica, el proceso de creación de un derecho constitucional común o genérico en el sur global ha acontecido con particular intensidad en el contexto de los países latinoamericanos. Sus afinidades contextuales y jurídicas, así como su natural disposición

13 Mariela Morales Antoniazzi, «El Estado abierto como objetivo del ius constitutionale commune», en: Armin von Bogdandy - Héctor Fix Fierro - Mariela Morales (coords.), Ius Constitutionale Commune en América Latina: rasgos, potencialidades y desafíos. México D. F.: UNAM-IIJ - Instituto Max Planck de Derecho Público, Comparado y Derecho Internacional, 2014. 
al diálogo y la apertura en la construcción de sus sistemas jurídicos, han venido conformando progresivamente un cuerpo de doctrina constitucional genérica que constituye la base de la interamericanización del derecho.

La globalización del derecho en América Latina, hasta hace relativamente poco tiempo, dejó de estar determinada por países del primer mundo que eran exportadores de derecho, hacia países del tercer mundo: importadores con escasa o nula autoridad retributiva en esta relación de poder y dependencia. Para comprender las particularidades de este cambio adquiere relevancia el concepto «interamericanización». La soberanía y las fronteras siguen fracturadas pero ya no solo para dejar entrar flujos sino también para exteriorizarlos. Estándares normativos se crean y desarrollan a partir del diálogo y la interacción, y no solo ya a partir de la apropiación o copia. En este punto radica la importancia, reiterada por el ICCAL, del comparativismo en el proceso de creación y desarrollo del derecho en la región. Los argumentos y las doctrinas no tienen que acreditar su nacionalidad para acreditarse como útiles o razonables ${ }^{14}$.

El referente hacia donde miraban los países cuando iban a cambiar sus constituciones era Estados Unidos ${ }^{15}$ y, contemporáneamente, España. Los textos constitucionales empezaron, desde hace 25 años, a parecerse más entre ellos que a seguir un único modelo extranjero de texto constitucional. Constituciones se proclamaron con afinidades orgánicas y dogmáticas. Pueden rastrearse patrones de interacción y apropiación formal-orgánica y sustantivo-dogmática entre las constituciones latinoamericanas, tanto las que cambiaron (Colombia, Ecuador, Bolivia y Venezuela) como las que introdujeron reformas (Argentina ${ }^{16}$, Costa

${ }^{14}$ Ivan Rand, graduado de Harvard y magistrado de la Corte Suprema de Canadá, al descubrir que otros miembros del Tribunal eran reticentes a utilizar algún enfoque o criterio proveniente del derecho constitucional estadounidense, procedió con éxito a adoptarlos en decisiones que fueron respaldadas por el Tribunal, pero para conseguirlo debió omitir indicar su origen estadounidense. Véase, Edward McWhinney, "Judicial Review in a Federal and Plural Society: The Supreme Court of Canada», en: John R. Schmidhauser (ed.), Comparative Judicial Systems. Challenging Frontiers in Conceptual and Empirical Analysis. Boston: Butterworths - International Political Science Association, 1987, p. 63.

15 Russell H. Fitzgibion, «The Process of Constitution Making in Latin America», en: Comparative Studies in Society and History, Vol. 3, No. 1, 1960. Michel Rosenfeld - András Sajó (eds.), The Oxford Handbook of Comparative Constitutional Law. Oxford University Press, 2012, «Introduction».

16 Se modernizó la Constitución introduciendo un catálogo más amplio de derechos, medidas para el ejercicio de la ciudadanía democrática y normas para la defensa de la Constitución misma. Se crearon nuevos órganos de control. Se ha criticado no obstante por reforzar el sistema presidencial y reproducir la democracia delegativa. Véase, Raúl Alfonsín, Constitución y consenso. A propósito de la reforma Constitucional. Buenos Aires, Tiempo de ideas, 1996. 
Rica ${ }^{17}$ y México ${ }^{18}$ ). La creación de constituciones y el desarrollo de la doctrina jurídica y la jurisprudencia local, dejaron de depender exclusivamente de los desarrollos de los grandes polos intelectuales del derecho: Estados Unidos, Francia, Italia y Alemania, cuyas normas, instituciones y teorías se importaban y adoptaban con baja intensidad de transformación local. En la actualidad países de la región también han sido referentes para sus pares en estos procesos de cambio constitucional y de creación y desarrollo del derecho.

América Latina dejó de ver con encandiladora reverencia a las potencias productoras de legislación y de ciencia jurídica ${ }^{19}$, y pasó a reconocer la validez de lo que se cosechaba en la zona y no solo de lo que se importaba. Como sucede con la globalización comercial, el consumidor local ha tendido a atribuir mayores niveles de calidad y prestigio a los productos extranjeros: carros, relojes y computadores, así como legislación, instituciones políticas y ciencia jurídica. Para los países del sur global los atributos que ofrece la comparación (apropiación, préstamo, trasplante...) han sido fuente de inspiración y de legitimación ${ }^{20}$. Uno de los desafíos de la interamericanización del derecho es dotar de mayor autoridad y legitimidad a los productos jurídicos que siembra y cosecha.

Ante la pérdida de hegemonía de potencias jurídicas como fuentes casi exclusivas de doctrina constitucional y creación de derecho en la región, la interamericanización del derecho se plantea como un fenómeno derivado de la globalización del derecho en el contexto latinoamericano. El derecho constitucional genérico reconocible hoy en América Latina, con los importantes elementos jurídico-dogmáticos que provienen de los países tradicionalmente influyentes en

${ }^{17}$ Se instituyó la jurisdicción constitucional y creó una sala especializada de la Corte Suprema para tramitar los recursos de amparo y los vetos por razones de inconstitucionalidad (1989), estableció el derecho a un ambiente sano (1994) y determinó que la ciudadanía es irrenunciable (1995). Hubo otras reformas, tales como la de 2003 que adoptó la reelección presidencial que había sido abolida por la reforma constitucional de 1969.

${ }^{18}$ Se ha desarrollado el control de constitucionalidad (1994) y sobre derechos humanos, que incluye el bloque de constitucionalidad y el principio de interpretación a favor de los derechos más amplios (2011).

19 Durante los siglos XIX y xx se trató sobre todo, además de algunas instituciones jurídicas estadounidenses, de la ideología jurídica liberal que predominaba en Francia, Italia y Alemania. Kennedy identifica constituciones, tratados y cartas de derechos como los instrumentos jurídicos definitorios y característicos de la época contemporánea y analiza las posibles causas de la difusión global de la institución de la revisión judicial. Véase su influyente trabajo «Three Globalizations of Law and Legal Thought: 1850-2000», en: David M. Trubek - Alvaro Santos (eds.), The New Law and Economic Development: A Critical Appraisal. New York, Cambridge University Press, 2006.

${ }^{20}$ Michel Rosenfeld - András Sajó (eds.), The Oxford Handbook of Comparative Constitutional Law. Oxford University Press, 2012, «Introduction». 
la construcción de cánones jurídicos, está construyendo su legitimidad y autoridad en la dimensión regional donde acontecen hoy intensos flujos e intercambios.

Dentro de las fuentes de este derecho constitucional genérico latinoamericano, hay que destacar el papel desempeñado por académicos, jueces, funcionarios e instituciones como ONG, entre otros sujetos, que durante las dos últimas décadas transformaron el canon jurídico existente (académico, judicial y pedagógico), del positivismo jurídico alemán y del derecho civil decimonónico con clara influencia del racionalismo francés y su exégesis. Este canon se reinterpretó y expandió a medida que se empezaba a dar respuesta a las transformaciones sociales y culturales expresadas en el contenido normativo de nuevas disposiciones constitucionales.

Otra fuente significativa de la interamericanización del derecho, que ha contribuido con la expansión del canon, es la jurisprudencia interpretativa de la Corte Interamericana en ejercicio del control de convencionalidad como mecanismo judicial creado al interior del Sistema Interamericano de Protección de los Derechos Humanos para propugnar por la defensa de los principios democráticos y los derechos consagrados en la Convención Americana. Las obligaciones internacionales relativas a la protección de los derechos consagrados en la Convención Americana, condicionan la interpretación de las normas jurídicas y prácticas administrativas.

Las constituciones latinoamericanas no obligan ni exhortan a las cortes a considerar el derecho de otros países o el derecho internacional cuando interpretan sus provisiones, como sí hace la Constitución Sudafricana $(\$ 39,1)$. No obstante, estamos presenciando en el mundo, y en América Latina en particular, el nacimiento de una doctrina constitucional genérica que se está creando por los procesos de interamericanización. Se está convirtiendo en una especie de «lengua franca» en la que se comunican los países con independencia de su pasado y de su cultura. El uso judicial y doctrinario del derecho extranjero y del derecho internacional, no es un fenómeno aislado sino un subproducto de este proceso de globalización del derecho en América Latina, es decir, de la progresiva interamericanización del derecho. Se ha estimulado por los avances en las facilidades del transporte y la comunicación globales, así como por la intensificación de los lazos políticos, económicos, culturales y jurídicos entre los países ${ }^{21}$.

${ }^{21}$ Para Alexander Somek, profesor de derecho en la Universidad de Iowa, el instituto de derecho constitucional comparado más importante del mundo, es la Corte Suprema de Israel. Alexander Somek, «The Deadweight of Formulae: What Might Have Been the Second Germanization of American Equal Protection Review», en: 1 University of Pennsylvania Journal of Constitutional Law, 284, 1998. 
Dentro de las razones que explican el hecho de que profesores, académicos, activistas y jueces de distintos países apliquen cada vez más normas, teorías o instituciones similares del derecho extranjero o del internacional, a circunstancias similares, se encuentran: (1) los tribunales constitucionales experimentan una necesidad teórica afín de justificar instituciones y prácticas —algunas veces activistas, algunas veces contramayoritarias- como el control judicial de constitucionalidad, la declaratoria de estados de cosas inconstitucionales y la práctica de proferir ordenes complejas. (2) Las cortes emplean habilidades comunes se enfrentan a los retos de la creatividad judicial para resolver problemas en casos constitucionales y (3) enfrentan influencias entrecruzadas que fomentan la adopción de normas y prácticas jurídicas similares ${ }^{22}$.

Incluso en uno de los países más reacios a utilizar el argumento comparado, como los Estados Unidos, sus insulares (comparativamente hablando) academia y enseñanza jurídicas, así como su poder judicial, están adquiriendo mayor consciencia de la importancia del derecho extranjero ${ }^{23}$. «Después de muchos años de petulante confianza en sí misma [smug self-assurance] la educación jurídica en Estados Unidos muestra ahora un marcado interés por los sistemas jurídicos y los problemas constitucionales de otros países. Es seguro que este interés recién descubierto es parte de la exportación de la cultura jurídica estadounidense hacia otras tierras, pero también refleja una creciente curiosidad acerca de cómo las cosas podrían ser realizadas de otra manera en Estados Unidos» ${ }^{24}$.

La actual mayoría de magistrados de su Corte Suprema se ha mostrado dispuesta a considerar como fuentes a los materiales jurídicos de otros países y del derecho internacional ${ }^{25}$. Las palabras de uno de los magistrados que más se ha expresado a favor, Stephen Breyer, no son más una rareza: «Esta Corte ha considerado por mucho tiempo relevante e instructiva la forma como cortes extranjeras han aplicado estándares parcialmente comparables con nuestros propios

${ }^{22}$ La figura del estado de cosas inconstitucional, creada en el tribunal colombiano para enfrentar las situaciones de violaciones graves y estructurales de derechos fundamentales sobre las que las medidas de política existentes no permiten vislumbrar un cambio positivo al respecto, ha sido receptada en contextos académicos y judiciales de países como México, Perú y Brasil.

${ }^{23}$ Robert Post, «The Challenge of Globalization to American Public Law Scholarship», en: 2 Theoretical Inquiries in Law. 323, 2001. David Schneiderman, "Comparative Constitutional Law in an Age of Economic Globalization», en: Vicki C. Jackson - Mark Tushnet (eds.), Defining the Field of Comparative Constitutional Law. Westport, CT.: Praeger, 2002.

24 Jack BALKIN-SANFORD LEvinSON, «Los cánones en el derecho constitucional» (Trad. de Leonardo García J.), en: Miguel Carbonell - Leonardo García Jaramillo (eds.), El canon neoconstitucional. Madrid, Trotta, 2010.

${ }^{25}$ En casos complejos y en áreas polémicas como la pena capital y los derechos para parejas homosexuales. Véase, David Law, «Generic Constitutional Law». Op. cit. 
estándares constitucionales en circunstancias parcialmente comparables. (...) La disposición a considerar perspectivas judiciales extranjeras en casos comparables, no es sorprendente en una Nación que desde su nacimiento ha otorgado una «consideración respetable a las opiniones de la humanidad» ${ }^{26}$.

\section{REALIDADES FÁCTICAS Y JURÍDICAS AFINES QUE REFUERZAN EL COMPARATIVISMO}

La interamericanización del derecho ha encontrado en la Corte Constitucional Colombiana uno de sus actores más determinantes. Se encuentra dentro de los tribunales más activistas y que mayor uso hace del argumento comparado en sustento o como ilustración de distintas posiciones. Recurre con frecuencia tanto a la teoría política y constitucional, como a sentencias y argumentos esgrimidos por otros tribunales. Esta apertura hacia el derecho comparado ha derivado en un influjo de teorías, doctrinas y jurisprudencia trasnacionales en la doctrina local, en la práctica del derecho y en su enseñanza, no solo en Colombia sino en otros países de la región.

Ante desafíos sociales y culturales similares, sentencias de la Corte han sido fuente permanente de creación, desarrollo y enseñanza del derecho. Precedentes y herramientas judiciales han sustentado subreglas o posiciones que, en desarrollo de la cláusula del Estado Social y Democrático de Derecho, del catálogo de derechos, de principios como la colaboración armónica entre las ramas del poder público, el goce efectivo de los derechos, la realización de los derechos como fin del Estado y la salvaguarda a la integridad de la Constitución, han contribuido en la interpretación, creación y desarrollo del derecho constitucional, con incidencia en la legislación en general. Para Landau, la Corte Constitucional colombiana es el tribunal judicial más poderoso del mundo ${ }^{27}$.

Los rasgos pioneros que marcaron el cambio de paradigma constitucional colombiano en 1991, tanto por el resultado del proceso constituyente como sobre todo por la jurisprudencia de la Corte, irradiaron procesos de reforma

${ }^{26}$ Opinión sostenida en su disenso del caso Knight v. Florida, 528 U. S. 990, 1999, p. 997. La cita interna corresponde a un fragmento de la primera parte de la Declaración de Independencia. Traducción propia.

${ }^{27}$ David E. Landau, Beyond Judicial Independence: The Construction of Judicial Power in Colombia. Ph. D. Dissertation. Department of Government Harvard University, Cambridge, 2004. Cito de la versión manuscrita facilitada por el autor; «Political Institutions and Judicial Role in Comparative Constitutional Law», en: Harvard International Law Journal. Vol. 51, n. ${ }^{\circ}$ 2, 2010. 
constitucional adelantados en Venezuela, Ecuador y Bolivia ${ }^{28}$, y han sido referentes importantes en otros países como México, Perú, Brasil y Argentina. El nuevo constitucionalismo colombiano supone un punto de inflexión que determina en Latinoamérica el inicio y establece las bases para el desarrollo de una forma constitucional propia durante las dos últimas décadas, por lo que marca el inicio de la transformación paradigmática de la doctrina constitucional latinoamericana ${ }^{29}$.

El diálogo entre magistrados de las altas cortes nacionales y regionales, que crece y se intensifica, se ha realizado sobre todo mediante citaciones mutuas e interacciones cada vez más directas ${ }^{30}$. Además de las citas y referencias jurisprudenciales entre cortes, la realización de congresos episódicos y fugaces visitas de magistrados a otros tribunales ${ }^{31}$, los principales rasgos que pueden identificarse del ius commune latinoamericano constituyen una razón más profunda y sistemática para contemplar la expansión de la interamericanización del derecho. Destacaría:

- Adopción, de forma casi invariable respecto del contexto germano y español, por ejemplo, del modelo ideológico y la formula política del Estado social y democrático de derecho, fundado en la dignidad humana y cuya soberanía radica en el pueblo ${ }^{32}$.

28 Albert Noguera Fernández-Marcos Criado De Diego, «La Constitución colombiana de 1991 como punto de inicio del nuevo constitucionalismo en América Latina», en: Estudios Socio-Jurídicos, Vol. 13, n. ${ }^{\circ}$ 1, enero-junio, 2011.

29 Sobre el constitucionalismo colombiano, en perspectiva comparada, véanse las contribuciones de Rodrigo Uprimny («The Recent Transformation of Constitutional Law in Latin America: Trends and Challenges»), César Rodríguez («Beyond the Courtroom: The Impact of Judicial Activism on Socioeconomic Rights in Latin America») y Manuel José Cepeda («Social and Economic Rights and the Colombian Constitutional Court») en el Vol. 89, n. ${ }^{\circ}$ 7, 2011, de Texas Law Review.

30 Anne-Marie Slaughter, A New World Order. Princeton University Press, 2004, p. 70.

31 El incremento en el diálogo judicial se ha ponderado sobre todo como promotor de la globalización del derecho de los derechos humanos. Véase, Claire L’HeureuX-Dubé, «The Importance of Dialogue: Globalization and the International Impact of the Rehnquist Court», en: 34 Tulsa Law Journal 15, 1998. Slaughter argumenta, en este sentido, que el aumento del contacto y la interacción personal entre magistrados constitucionales de diferentes países, está promoviendo una polinización cruzada jurídica (legal cross-fertilization) en campos como los derechos humanos y el derecho constitucional. $C f r$. Anne-Marie Slaughter, «Judicial Globalization», en: 40 Virginia Journal of International Law 1103, 2000.

32 Colombia es un Estado social de derecho (art. 1), Venezuela es un Estado democrático y social de Derecho y de Justicia (art. 2), Ecuador es un Estado constitucional de derechos y justicia, social, democrático, soberano, independiente, unitario, intercultural, plurinacional y laico (art. 1) y Bolivia que se constituye en un Estado Unitario Social de Derecho Plurinacional Comunitario, 
- Ampliación de los catálogos de derechos incluyendo no sólo sociales sino también derechos al ambiente sano.

Además de reiterar en la importancia de salvaguardar la libertad, se incluyeron disposiciones que amparan el derecho a la igualdad, prohíben la discriminación y promueven la adopción de medidas en favor de grupos discriminados o marginados (affirmative action). Otras disposiciones amparan principios como solidaridad, pluralismo, justicia, dignidad humana, autodeterminación nacional y responsabilidad social. Se incluyeron asimismo cláusulas de derechos innominados para no restringir los derechos a los incluidos expresamente en la constitución.

- Superación de la adscripción de los Estados como confesionales. Separación entre la iglesia y el Estado. Si bien se invoca el nombre o la protección de Dios en los preámbulos de las nuevas constituciones, se consagraron disposiciones que amparan la libertad de cultos, lo cual hace laicos a los estados latinoamericanos. El fundamento de esta forma de Estado es la igualdad, la garantía de los derechos sin configuraciones relativas a alguna fe particular, la soberanía popular y la protección de las creencias de las minorías ${ }^{33}$.

- Consagración de formas de protección judicial, como el recurso de amparo, para hacer efectivos los derechos y principios al aplicar la constitución no sólo respecto de los particulares y el Estado, sino también de las relaciones entre particulares.

- El nuevo constitucionalismo latinoamericano es el constitucionalismo de la diversidad. Principios como pluralismo, igualdad y dignidad se dotaron de particular efectividad por su consagración constitucional y por la posibilidad de ratificación de tratados internacionales que amparan derechos minoritarios.

libre, independiente, soberano, democrático, intercultural, descentralizado y con autonomías (art. 1). Aunque la Constitución de Perú no adscribe formalmente al Estado Social de Derecho, el art. 3. consagra una cláusula de derechos innominados según la cual la enumeración de los derechos no excluye otros que se fundan en los principios del Estado democrático de derecho.

${ }^{33}$ Hay diferencias de grado. Algunas constituciones conservan algún rasgo confesional («El Gobierno federal sostiene el culto católico apostólico romano» (Argentina); «la religión católica es la del Estado» y se restringe la libertad de cultos a que no se oponga a la moral universal y a las buenas costumbres (Costa Rica); y «la religión católica es la de la mayoría de los panameños» y se limita la libertad de cultos al respeto a la moral cristiana y al orden público» (Panamá). La Constitución Peruana señala que «Dentro de un régimen de independencia y autonomía, el Estado reconoce a la Iglesia Católica como elemento importante en la formación histórica, cultural y moral del Perú, y le presta su colaboración») y otras reconocen la separación entre Iglesia y Estado (constituciones boliviana, brasilera, ecuatoriana, mexicana, nicaragüense, paraguaya y venezolana). 
La protección y promoción de las diversidades se establece como principio constitucional. No sólo se reconoce la importancia de la promoción de la igualdad y a la prohibición de discriminación, sino que a los grupos históricamente discriminados se les han otorgado tipos especiales de protección. Por ejemplo, se determinaron circunscripciones especiales indígenas de representación política y se reconocieron lenguas autóctonas como oficiales $^{34}$.

- Apertura al derecho internacional sobre todo en materia de derechos humanos donde se le confiere especial consideración a los tratados que los amparan, lo cual ha conducido a reconocer estándares internacionales de derechos a partir, básicamente, del bloque de constitucionalidad que integran las normas de un determinado ordenamiento jurídico debido a la ratificación de un acuerdo internacional de derechos ${ }^{35}$.

- Descenso de la ley del sitial que tradicionalmente ocupaba en el podio de las fuentes del derecho. La jurisprudencia se ha involucrado en el estudio de problemas teóricos generales sobre la naturaleza general del derecho y su relación con la justicia y la moral. La jurisprudencia se ha constituido en muchos casos en la fuente de la conciencia jurídica, es decir, en la principal forma como se comprende el derecho.

- Las constituciones son ahora más extensas, debido a la incorporación de nuevas disposiciones, y más rígidas porque establecen condiciones de modificabilidad de manera más estricta respecto del procedimiento legislativo.

La rigidez de la constitución es, conjuntamente con su garantía jurisdiccional por un tribunal independiente, su naturaleza normativa y la posibilidad de interpretarse extensivamente, uno de los principales elementos que contribuyen al proceso de constitucionalización del derecho.

- Las nuevas constituciones consagran mecanismos para su reemplazo (Bolivia, 2009; Colombia, 1991; Ecuador, 2008; Guatemala, 1985; Nicaragua, 1987; Paraguay, 1992; Venezuela, 1999; y Panamá después de la reforma de 2004$)^{36}$.

${ }^{34}$ Las constituciones que realizaron los mayores cambios constitucionales respecto de la cuestión indígena, fueron las de Colombia, Venezuela, Ecuador y Bolivia.

35 En Colombia por ejemplo los derechos de las víctimas del conflicto armado a verdad, justicia y reparación, han sido reconocidos en virtud del bloque de constitucionalidad.

36 Esta reforma tiene un lado negativo en algunos casos porque refuerza el poder del presidente para reformar o reemplazar a la Constitución. Las constituciones de Venezuela y Ecuador otorgan al poder ejecutivo la facultad exclusiva de convocar a un referendo para aprobar enmiendas 
- Robustecimiento de la democracia y ampliación los canales para la participación política. Ampliación de la facultad de iniciativa legislativa a otros organismos además del parlamento. Con diferencias contextuales se evolucionó de una democracia representativa a una democracia participativa.

- Se avanzó hacia la creación de mecanismos de justicia constitucional, sobre todo, mediante la creación de tribunales independientes encargados de proteger la superioridad de la constitución dentro del sistema jurídico y la garantía de sus provisiones.

- Además de los tribunales constitucionales, se crearon otras instituciones como organismos electorales autónomos, defensorías públicas ${ }^{37}$ y juntas monetarias.

- Se dotó de mayor equilibrio a los órganos de poder, lo cual en algunos casos se ha visto menguado por el correlativo poder de cooptación institucional que ha conseguido el presidente. A ello se articula alguna tendencia a las reformas para conseguir la reelección presidencial, lo cual ha conducido a un reforzamiento del híper-presidencialismo.

Se observa una preocupación constitucional por fortalecer el poder judicial y garantizar la separación entre las ramas del poder público, fortaleciendo la concepción de los frenos y contrapesos que, si bien se encontraba reconocida, la falta de efectividad de los órganos creados para resguardarla la tornaba una garantía inocua.

\section{EL IUS CONSTITUTIONALE COMMUNE Y LA INTERAMERICANIZACIÓN DEL DERECHO}

El concepto «interamericanizacion» está inescindible y destacadamente ligado al Ius Constitutionale Commune en América Latina (ICCAL) ${ }^{38}$. Se trata de la concepción jurídica que mayor potencial tiene en la región actualmente para comprender la interamericanización académica y judicial del derecho. Procura igualmente analizar y proyectar rumbos de acción hacia un constitucionalismo transformador de las desigualdades sociales y políticas que aquejan a los países

a la constitución o para que se consulte a la ciudadanía si debería elegirse una asamblea que promulgue una nueva constitución.

37 Mecanismos judiciales y formas de «ombudsman» los consagran las constituciones de Argentina, Colombia, El Salvador, Guatemala, Honduras, Panamá, Paraguay, Perú, República Dominicana y Venezuela.

38 En Google Scholar las primeras entradas del concepto, remitan a foros y trabajos desarrollados en el contexto del proyecto ICCAL. 
de la región. Tiene por tanto aspiraciones descriptivas y prescriptivas. La interamericanización del derecho promueve la creación de un derecho constitucional común latinoamericano que, a su vez, propicia la confluencia entre el constitucionalismo regionalmente configurado, el derecho internacional público y el discurso sobre los derechos humanos ${ }^{39}$.

El proyecto se enfoca en las nuevas formas de comprender, analizar y proyectar debidamente los elementos medulares del derecho público en el contexto de los procesos de globalización económica y jurídica occidentales. Los objetivos fundamentales del ICCAL son: la garantía de los derechos humanos, el robustecimiento de la democracia y la consolidación del estado de derecho. La cuestión cardinal sería cómo el derecho positivo - la normativa y su concreción jurisprudencial—, tanto local como regional, y el derecho constitucional genérico construido en los últimos años, pueden realmente contribuir a transformar realidades sociales y políticas concretas. Su cometido pionero hacia la descripción y el análisis de los orígenes, evolución, características, desafíos y destinos posibles del derecho constitucional latinoamericano, hace al ICCAL el enfoque más ambicioso y con mayor proyección de los que actualmente propugnan por un constitucionalismo transformador.

Hechos de distinta naturaleza constituyen el punto de partida del concepto. El primero es el hecho social de pobreza y desigualdad en la región. El segundo es el hecho político en virtud del cual los órganos representativos han mostrado desidia, incapacidad o inacción para acometer reformas urgentes, lo cual a nivel inmediato se refleja en una deficiencia de políticas públicas estructurales y un desencanto frente a la política. Esto último ha derivado en una baja participación política que se manifiesta en abstención electoral y falta de interés por la res publica. Un tercer hecho, el institucional, refleja la esperanza social fincada en los jueces y los tribunales constitucionales para remediar distintos problemas, lo cual se refleja en su activismo progresista ${ }^{40}$.

39 Armin Von Bogdandy-Héctor Fix Fierro-Mariela Morales (coords.). Ius Constitutionale Commune en América Latina: rasgos, potencialidades y desafíos. México D. F.: UNAM-IIJ - Instituto Max Planck de Derecho Público, Comparado y Derecho Internacional, 2014.

40 No es un pleonasmo defender el activismo «progresista». Si bien todo progresismo es activista, no todo activismo es progresista. El progresismo siempre es activista porque implica trabajar y actuar para alcanzar grados de progreso individual y grupal en el contexto de derechos y principios como la igualdad, la libertad y la justicia. Reúne ideologías de centro izquierda y centro derecha contrarias al statu quo del conservadurismo de derecha. El progresismo en política es entonces activista, reformista y pragmático. Puede haber, en contraste, activismo no progresista, regresivo, es decir, un activismo en procura de recuperar tradiciones sociales y culturales relacionadas con el sexo, las libertades y la igualdad, por ejemplo, que no procuren lograr grado alguno de progreso. 
La conjunción de estos tres hechos (pobreza y desigualdad, incapacidad o inacción parlamentaria, y tribunales requeridos por la toma de decisiones progresistas) en países con constituciones normativas y derechos vinculantes, ha derivado en un inédito protagonismo judicial y en un empoderamiento político del juez que, en el contexto de la interamericanización del derecho, reclama por un diálogo entre cortes frente a la cuestión por cómo el constitucionalismo local y regional puede contribuir a transformar realidades sociales y políticas concretas.

La idea de soberanías porosas o fracturadas no es nueva tratándose de la construcción del discurso jurídico latinoamericano. La presencia de materiales de derecho extranjero en la creación de leyes, doctrinas jurídicas e instituciones políticas ha sido una constante no solo en Colombia sino en América Latina. La influencia, el trasplante y la presión por parte de contextos jurídicos extranjeros y comparados poderosos, han sido determinantes en la creación y el desarrollo del derecho y la política en la región.

A la decisión constitucional a favor de la apertura del derecho nacional al derecho internacional, se le ha denominado Estado abierto. En virtud de este concepto, el sistema jurídico dispone de canales para el influjo del derecho internacional público como fuente a partir de las cláusulas de apertura o reenvío, que son las disposiciones constitucionales que permiten interpretar armónicamente su texto con otros textos ${ }^{41}$. El desarrollo de la noción de Estado abierto, a su vez, conduce necesariamente a reconcebir un concepto central en la teoría del Estado, como es la soberanía, la cual reclama ahora la apertura hacia el derecho internacional. Se ha permeabilizado para filtrar en el derecho interno estándares normativos formales - provenientes de la jurisprudencia interamericana- e informales - a partir de la intensificación del diálogo entre las altas cortes nacionales-. Sobre todo en materia de derechos humanos, las fronteras no son ya las de los Estados sino las del conocimiento común compartido acerca de una idea de dignidad humana que ha evolucionado del ideario político a la dogmática jurídica para sustantivar el discurso jurídico de protección y promoción de los derechos humanos.

El comparativismo jurisprudencial, propiciado por el diálogo judicial, el activismo académico, las ONG y el litigio estratégico, propiciará mejores formas de creación del derecho local en la medida en que se aprovecharán experiencias vividas en otros contextos para evitar errores y promover aciertos ante fenómenos

${ }^{41}$ Un texto normativo concreto, un conjunto de textos normativos, un principio derivado de la jurisprudencia interpretativa como la igualdad o la dignidad humana, o un conjunto de principios como los del derecho internacional. 
como la contención al híper presidencialismo y la creatividad en la aplicación de la normativa constitucional garantista en contextos de pobreza y desigualdad.

El fundamento jurídico del ICCAL es principalmente la Convención Americana de Derechos Humanos, y su desarrollo jurisprudencial por parte de la Corte, así como doctrinas judiciales que han surgido en la región en respuesta a los desafíos que la realidad impone al derecho. Se fundamenta jurídicamente en otros elementos del constitucionalismo contemporáneo como la naturaleza normativa de la Constitución y la fuerza vinculante de los derechos. La noción que defiende de la Constitución se articula con aquellas concepciones en virtud de las cuales las constituciones contemporáneas no solo limitan el poder del Gobierno y el Congreso, sino que fundamentalmente amplían las exigencias a todos los poderes públicos que se encuentran vinculados a los derechos fundamentales.

Ningún proyecto que sustente un constitucionalismo transformador en América Latina sería defendible si no incorporase una concepción acerca de la inclusión en los sistemas social, económico y político. La inclusión plantea sobre todo desafíos a la transformación social mediante el constitucionalismo, en la garantía de los derechos sociales, que son precondiciones para el ejercicio de los derechos de libertad. Los derechos sociales procuran crear las condiciones materiales necesarias para lograr una mínima igualdad, que es esencial para el ejercicio efectivo de la libertad. El amparo de los derechos sociales sitúa a las personas en condición de poder hacer aquello que son libres de hacer. Como han sustentado Alexy, Bobbio y Ferrajoli, entre otros, los derechos sociales son fundamentales porque su satisfacción asegura los «pre-requisitos» de la democracia política, toda vez que solo su garantía puede aportar los presupuestos materiales imprescindibles del disfrute de los demás derechos.

\section{LOS CÁNONES EN EL DERECHO CONSTITUCIONAL: CUÁLES SON Y CÓMO TRANSFORMARLOS}

El ICCAL es un concepto que comporta un proyecto comprometido con la garantía de los derechos humanos, el robustecimiento de la democracia y la consolidación del estado de derecho, a partir del diálogo entre cortes, la inclusión social y política, y el pluralismo normativo, y mediante, entre otros, un mayor uso del derecho comparado y la argumentación jurídica basada en principios. Toda vez que la globalización ha tenido importantes efectos en la difusión y el desarrollo, local y regional, del conocimiento jurídico, es pertinente identificar las áreas estratégicas donde puede ejercerse influencia en procura de 
contribuir a la evolución y consolidación de los procesos de interamericanización del derecho.

Resulta útil definir el tipo, la naturaleza y el alcance de los cánones jurídicos que han empezado a construirse en la región a partir de normas, teorías, dogmática y ciencia jurídica que se reciben creativamente desde cánones trasnacionales. La interamericanización del derecho se fortalecerá en la medida en que se identifiquen e intervengan adecuadamente tales cánones. La propuesta de Jack Balkin y Sanford Levinson ${ }^{42}$, profesores de las universidades de Yale y Texas, respectivamente, es pertinente a este respecto. Identifican tres formas como la cuestión de los cánones, de uso común en la literatura y en las humanidades, puede articularse en el constitucionalismo, es decir, qué es y qué debiera ser canónico en el derecho. «No hay mejor forma de entender una disciplina — sus temas básicos, sus inquietudes e intereses actuales - que estudiar qué piensan sus miembros sobre lo que es canónico para esa disciplina. El estudio de los cánones y la canonicidad es la llave para ingresar a los secretos de una cultura y a sus formas características de pensamiento» ${ }^{43}$.

Primero, podríamos preguntar cuáles casos y materiales jurídicos importantes deberían enseñarse y difundirse en las facultades de derecho (canon pedagógico). Segundo, podríamos preguntar sobre qué casos claves y materiales debería estar enterada una persona educada en un debate serio sobre cuestiones centrales del desarrollo constitucional (canon de cultura general). Tercero, podríamos preguntar cuáles casos claves y materiales debería conocer cualquier académico serio - a diferencia del abogado promedio o la persona bien educada- y tomar en cuenta cualquier teoría seria del derecho constitucional (canon teórico-académico).

Las realidades políticas que acontecen en América Latina, así como la complejización de fenómenos jurídicos nacionales debido a los avances del derecho público interamericano, reclaman la emergencia de conceptos que sofistiquen las categorías con las cuales describimos nuevos fenómenos y que señalen rumbos de acción. El desarrollo y la consolidación de un canon teórico-académico plantean una tarea fundamental a la academia jurídica latinoamericana, como es la depuración y sofisticación conceptual que conduzca a mejores prácticas, para posteriormente sistematizar los nuevos materiales jurídicos que surjan.

Respecto del canon pedagógico, debido a que la casuística y la literatura que debe conocer un estudiante de derecho, un académico y un ciudadano bien informado, trascienden las fronteras nacionales, se requiere orientar el abordaje y el análisis del derecho internacional. Una vez se ha definido el control de conven-

\footnotetext{
${ }^{42}$ Jack BALKIN-Sanford LEvinson, «Los cánones en el derecho constitucional». Op. cit.

43 Ibidem, p. 36.
} 
cionalidad como de naturaleza difusa y su ejercicio como de oficio, porque se realiza independientemente sea o no invocado por las partes ${ }^{44}$, los jueces nacionales deben ejercerlo, adicionalmente a los controles de legalidad y constitucionalidad. Se impone entonces un reto adicional que deben afrontar, no solo los jueces, sino también los profesores, los estudiantes y los académicos en general, como es el conocimiento de los principales precedentes sentados por la Corte Interamericana y por otras cortes internacionales. El control de convencionalidad, y la defensa de su naturaleza difusa, contribuye a configurar y expandir el derecho constitucional común.

En las reformas a los planes de estudio jurídicos se debe introducir o fortalecer el derecho internacional público de cara a los progresos que ha alcanzado la interamericanización del derecho en la región. Dentro de los casos estaría la escasamente estudiada jurisprudencia interpretativa de la Corte Interamericana y dentro de los materiales aquellos que integran el derecho constitucional producido en el sur global, así como las experiencias exitosas de los países de la región en las formas de solucionar sus conflictos constitucionales. El derecho comparado no debe ser más una materia optativa en la formación jurídica.

Excepto por la difusión de literatura extranjera, que por traducciones se está haciendo con particular dinamismo en la región desde hace poco más de dos décadas, el estudio del derecho internacional y extranjero, así como la teoría, los métodos e importancia del derecho comparado, son aún asuntos complementarios cuando no insulares en la enseñanza del derecho. La gran mayoría de estudiantes se forma en las facultades de derecho, incluso en algunas reconocidas - $\mathrm{O}$ autoproclamadas - como de elite, con desconocimiento del derecho comparado, de la jurisprudencia interamericana y de otras experiencias exitosas regionales o internacionales en la solución de conflictos. A pesar de la reconocida importancia de las fuentes del derecho extranjero e internacional para la doctrina, la enseñanza y la práctica del derecho, en la vida intelectual de la judicatura, la pedagogía e incluso en parte de la academia, estas materias aún no se consideran un campo central.

La academia tiene también un rol fundamental que desempeñar en la formación jurídica de los estudiantes y de los jueces. ¿Cómo exigirle a un juez que recurra al comparativismo en la doctrina o la jurisprudencia extranjera e internacional? Law cuestiona la posibilidad de que a los jueces se les exija, sin más, implementar esta sugerencia en su trabajo ordinario, debido a que en sus estudios no se le capacitó para ello. «Por ejemplo, ¿qué tal si los abogados y jueces esta-

${ }_{44}$ Opinión de Ferrer Mac Gregor, como juez ad hoc, en el Caso Almonacid Arellano vs. Chile, sentencia de 26 de septiembre de 2006. 
dounidenses no son capaces de nada más que de «generalizaciones superficiales» sobre la práctica jurídica en otros países? Qué tal si prueban ser tan amateur en el análisis jurídico comparado como son, digamos, en la historia o en la economía» ${ }^{45}$.

Resulta pertinente la demanda que plantea Dworkin por un juez que si bien no sea filósofo en sentido profesional, esté familiarizado con alguna parte de la principal literatura filosófica. «Los jueces y los filósofos no comparten simplemente temas y asuntos entrecruzados, como los astrónomos y los astrólogos. Por el contrario, los objetivos y los métodos de los jueces incluyen los de los filósofos: ambas profesiones apuntan más exactamente a formular y entender mejor los conceptos claves en los cuales se expresan nuestra moralidad política predominante y nuestra Constitución». Parecería natural por tanto esperar que los jueces tengan alguna familiaridad con la literatura filosófica, así como esperamos que la tengan con la economía y, en el caso de los jueces constitucionales, con la historia constitucional. «Lo que hacen los jueces es de una gran importancia, no sólo para las partes implicadas en el proceso sino también, particularmente en el derecho constitucional, para la gobernabilidad de la Nación. ¿Si los problemas que afrontan han sido debatidos por personas educadas, hombres y mujeres, que les dedicaron sus vidas a estas cuestiones, cómo los jueces pueden ignorar de manera responsable lo que estas personas han escrito?» ${ }^{46}$.

El canon de cultura general se conforma y fortalece en la medida en que la opinión pública y profesionales de otras disciplinas, tengan elementos de juicio para debatir sobre cuestiones de naturaleza constitucional sensibles moral o políticamente. La academia latinoamericana debe aprender de miembros de comunidades más consolidadas, como Ronald Dworkin, Michael Sandel y Sanford Levinson, entre otros, que además de libros y artículos académicos, y participación en grupos especializados de discusión, muestran en su obra un permanente interés por influenciar debates coyunturales sobre aspectos sensibles del derecho constitucional y la política democrática.

Dworkin publicó más de 100 textos, entre columnas de prensa y artículos de difusión, sobre aborto, eutanasia, matrimonio igualitario, restricciones a la pornografía y grados de admisibilidad de discursos que afectan minorías. Criticó nombramientos y posiciones de magistrados de la Corte Suprema. Además de académico original e influyente, fue un genuino intelectual público. Levinson, en la presentación de Our Undemocratic Constitution, sostuvo que entre los múlti-

\footnotetext{
45 David S. Law, «Generic Constitutional Law». Op. cit., p. 740.

46 Ronald Dworkin, «¿Deben o pueden nuestros jueces ser filósofos?» (trad. de Leonardo García J.), en: Isonomía n. ${ }^{\circ}$ 32-abril, 2010.
} 
ples públicos que podría tener su libro, el principal era el de sus conciudadanos. «Este libro no pretende ser simplemente un libro académico. Obvio espero que sea leído por académicos y estudiantes de derecho, pero esa no es realmente la principal audiencia $\gg^{47}$. Articula su planteamiento con la tesis de los aspectos defectuosos de la Constitución Estadounidense, planteada por Dahl ${ }^{48}$, pero no con el objetivo de continuar un diálogo académico sino de sustentar sus posiciones ante la opinión pública. El libro plantea, de un lado, a la opinión pública las razones por las cuales considera necesaria una nueva convención constituyente y, de otro lado, a las facultades de derecho, la reconsideración que debe tener la forma como se enseña el derecho constitucional en la actualidad.

Estos ejemplos resultan relevantes para la academia jurídica latinoamericana. A partir de una comprensión de la necesidad de construir los cánones constitucionales en varios niveles y ante diversos escenarios, surgen desafíos a la academia comprometida con la interamericanización del derecho y con un constitucionalismo transformador de las desigualdades sociales y políticas. Se plantean al menos dos. Primero, hacia el poder judicial que en la región no ha sido objeto de crítica. La academia ha tenido en general una deferencia acrítica frente al trabajo del tribunal constitucional aun cuando este control es uno de los más importantes que le corresponde realizar en las nuevas democracias constitucionales. Un mayor compromiso crítico y propositivo frente a los desafíos locales de implementación de la normativa constitucional y convencional, es fundamental para enfrentar la objeción típica, ante casos de activismo judicial progresista, de ¿Quis custodiet ipsos custodes? (¿quién controla al controlador?), es decir, ¿quién nos defiende del defensor de la constitución? Toda vez que este control es extra jurídico, porque está por fuera de las instituciones formales, el rol de la academia es esencial para controlar y vigilar la actividad de los tribunales constitucionales. Segundo, hacia la opinión pública. La academia debe contribuir a difundir buenas ideas y posiciones sustentadas ante casos controversiales, mediante, por ejemplo, columnas de prensa, participación en programas de radio y televisión, y con una activa participación en la configuración de una opinión pública deliberante y crítica.

47 Para una antología de columnas de prensa y trabajos de difusión de Dworkin, véase su libro, Derechos, libertades y jueces. (Leonardo García J. y Miguel Carbonell, eds.). México D. F.: Tirant lo Blanch, 2da ed., 2015. La presentación del libro de Levinson, en: www.youtube.com/ watch?v=R84OWIPlzqU

48 Robert DAHL, How Democratic is the American Constitution? New Haven: Yale University Press, 2002. 


\section{A MANERA DE CONCLUSIÓN}

La interamericanización del derecho, como construcción de un derecho constitucional común en América Latina desde los cánones pedagógico, teóricoacadémico y de cultura general, exige contar con academias (y no solo con tribunales) activistas. A los académicos progresistas comprometidos con el constitucionalismo transformador, les corresponde cuestionarse por formas efectivas de influenciar el diálogo constitucional entre académicos y jueces, pero también con la opinión pública. La academia jurídica latinoamericana tiene un papel fundamental que desempeñar, no solo en la sofisticación dogmática de categorías jurídicas, sino también en la veeduría a los organismos del poder público encargados de garantizar los derechos, en la contribución a la construcción de una opinión publica deliberativa y en el análisis crítico y la difusión de casos relevantes de tribunales internacionales, como la Corte Interamericana, y los tribunales del sur global.

La academia debe desempeñar un papel más proactivo en la acción política porque el cambio constitucional también debe fluir desde abajo en lugar de ser unilateralmente impuesto desde arriba ${ }^{49}$. Muchas veces a nivel local se construyen consensos políticos que luego son amparados judicialmente a nivel constitucional. Esta perspectiva tiene una dimensión académica donde la exigencia de un diálogo estaría en capacidad de ejercer influencia sobre la educación jurídica, la crítica y veeduría a las cortes, y el refinamiento teórico; y una dimensión política donde la academia plantea temas a la opinión pública para cohesionarla alrededor de, u orientarla hacia, determinados temas y a favor de particulares valores y principios. Cuando académicos se dirigen hacia la opinión pública, mediante columnas de prensa, participando en programas de radio y televisión, o haciendo accesibles los resultados de sus investigaciones, han mostrado formas de influenciar el debate público en temas política y moralmente sensibles.

Esta última dimensión resulta esencial en la justiciabilidad de los derechos sociales, como mecanismo fundamental de inclusión, porque el trabajo judicial por bien fundamentado y enfocado que esté, no será efectivo a menos que cuente con un respaldo político y social. En América Latina contamos con buenos ejemplos acerca de cómo importantes elementos del derecho constitucional han evolucionado en respuesta a perspectivas constitucionales sustantivas producto de la movilización de distintos grupos: los homosexuales en Argentina y Colombia, los indígenas en Ecuador y Bolivia, y los estudiantes en Chile.

49 Robert Post-Reva Siegel, Constitucionalismo democrático (Leonardo García J., ed. y trad.). Buenos Aires: Siglo XxI, 2013. 
Los tribunales han sido actores institucionales fundamentales que han traído con su jurisprudencia procesos de democratización, pero no están en capacidad de soportar enteramente el proyecto de un constitucionalismo transformador. Como sostiene Salazar Ugarte, ni los jueces por sí solos pueden ofrecer garantías plenas a los derechos ni éstos pueden demandar únicamente una protección jurisdiccional. Sin desestimar la función judicial, la justiciabilidad de los derechos, como fenómenos complejos, requiere de garantías políticas, económicas e incluso sociales, así como de un contexto cultural que los sustente ${ }^{50}$.

El cambio en el constitucionalismo latinoamericano aconteció sobre todo sobre la dogmática, es decir, la parte de la constitución que consagra derechos, incluye principios y adscribe a una determinada fórmula política. La distancia que aun separa a las provisiones constitucionales de la realidad social y política, plantea desafíos a la academia comprometida con un constitucionalismo transformador. El poder judicial es fundamental para alcanzar logros constitucionales, pero poco puede hacerse sin la política, sin la sociedad civil organizada. Desde hace 25 años que estos cambios se dinamizaron en América Latina, se regionalizaron patrones de desarrollo que la globalización creó para el derecho constitucional y comenzó así la interamericanización del derecho. Se ha desarrollado en parte, con diferencias contextuales, dentro de una red de influencias reciprocas en respuesta a preocupaciones comunes de naturaleza teórica y práctica.

La interamericanización responde además a la necesidad de crear conocimiento jurídico constitucional propio, crítico, que surja deductiva pero también inductivamente con elementos del canon teórico trasnacional, pero a partir de las circunstancias que aquejan a nuestras sociedades. A la academia interamericana le corresponde abrir caminos que determinen la creación de una conciencia jurídica propia alejada de la reproducción de conocimiento jurídico producido en otros contextos. Esta conciencia jurídica propia debe tener en cuenta la naturaleza híbrida de nuestras propias tradiciones jurídicas y nuestras necesidades.

Esto se puede hacer de dos formas: pretendiendo crear un canon jurídico propio o mediante la reinterpretación, necesariamente expansiva, del canon existente que va creando sub-cánones o cánones latinoamericanos. El derecho constitucional interamericano es más rico que el canon constitucional dominante en aspectos como el tipo de derechos, toda vez que incluye con particular fuerza a los derechos sociales, así como los derechos del ambiente, y mediante los mecanismos consagrados para protegerlos ha creado una dogmática jurídica

50 Pedro Salazar Ugarte, «La disputa por los derechos y el ius constitutionale commune», en: Armin von Bogdandy-Héctor Fix Fierro-Mariela Morales (coords.), Ius Constitutionale Commune en América Latina: rasgos, potencialidades y desafíos. Op. cit. 
que ha alcanzado logros importantes en su garantía. A partir de esta segunda alternativa se crea y consolida la interamericanización del derecho.

Sin duda desde el sur global se debe seguir investigando sobre las grandes teorías que hacen parte de cánones trasnacionales del pensamiento iusteórico y filosófico-político, pero debe procurarse aprender de ellas para construir mejores teorías intermedias sobre nuestras realidades. Colombia, donde la constitucionalización del derecho ha tenido efectos jurisprudenciales, doctrinarios y prácticos importantes —así como en alguna medida también su convencionalización ${ }^{51}$ — , representa un buen ejemplo para la región en cuanto a que el método como opera el derecho constitucional en sede judicial debe pasar del activismo judicialmente ensimismado, a uno más en sintonía con las perspectivas constitucionales de otros actores. Si bien globalizaciones de distinto tipo han existido desde antes de que el concepto se acuñara, la razón de su popularidad actual es el éxito en el fenómeno que procura describir y analizar. Las globalizaciones que acontecen en la actualidad son, entonces, más extensas, intensas y veloces. La interamericanización representa una muestra de ello.

El ICCAL puede orientar en la tarea de contribuir a desarrollar una perspectiva política para la sociedad civil pueda generar apoyos populares. Para mejorar la inclusión, amparar el pluralismo y defender la institucionalidad, se debe destinar inteligencia y energía a las formas de encontrar cursos de acción política que contribuyan al logro de los objetivos del constitucionalismo en términos de la garantía de los derechos humanos, el robustecimiento de la democracia y la consolidación del estado de derecho.

\section{REFERENCIAS}

BALKIN, Jack-SANFord, Levinson, «The Canons of Constitutional Law», en: 111 Harvard Law Review 963, 1998, vers. cast. de Leonardo García, en: Miguel

${ }^{51}$ El proceso de incorporación de los estándares sentados por la Corte Interamericana en las prácticas jurídicas locales, propicia otro proceso adicional y correlativo a la constitucionalización del derecho, como es su «convencionalización». Este concepto procura designar el proceso de incorporación de las doctrinas que, en desarrollo del control de convencionalidad, crea y fortalece este Tribunal en el proceso de resguardar ante casos concretos la integridad y el rango constitucional de la Convención Americana sobre Derechos Humanos. El progreso de convencionalización del ordenamiento jurídico es una de las consecuencias de la globalización del derecho en América Latina, es decir, de su interamericanización. Para una primera presentación de la relevancia del concepto, véase: Leonardo GarCía JarAmiLlo, «De la "constitucionalización” a la "convencionalización” del ordenamiento jurídico», en: Revista Derecho del Estado. En prensa. 
Carbonell - Leonardo García Jaramillo (eds.) El canon neoconstitucional. Madrid, Trotta, 2010.

Bogdandy, Armin von. "Ius Constitutionale Commune en América Latina: una mirada a un constitucionalismo transformador», en: Revista Derecho del Estado n. 34 (enero-junio) de 2015.

Bonilla, Daniel (ed.), Constitutionalism of the Global South. The Activist Tribunals of India, South Africa, and Colombia. Cambridge University Press, 2014.

- El constitucionalismo en el continente Americano. Bogotá: Siglo del Hombre - Universidad de los Andes, 2016.

Carbonell, Miguel - Jorge Carpizo - Daniel Zovatto (coords.), Tendencias del constitucionalismo iberoamericano. México D. F., UNAM-IIJ, 2009.

Drezner, Daniel W. «Globalization and Policy Convergence», en: International Studies Review, Spring, 2001.

DwOrkin, Ronald. «¿Deben o pueden nuestros jueces ser filósofos?» (trad. de Leonardo García J.), en: Isonomía n. 32-abril, 2010.

FitzGibBon, Russell H. "The Process of Constitution Making in Latin America», en: Comparative Studies in Society and History, Vol. 3, n. ${ }^{\circ}$ 1, 1960.

Held, David - Anthony McGrew (eds.), The Global Transformations Reader: An Introduction to the Globalization Debate. Cambridge: Polity, 2003.

Jackson, Vicki C. - Tushnet, Mark (eds.), Defining the Field of Comparative Constitutional Law. Westport, CT.: Praeger, 2002.

KEnNEDy, Duncan. «Three Globalizations of Law and Legal Thought: 1850-2000», en: David M. Trubek - Alvaro Santos (eds.), The New Law and Economic Development: A Critical Appraisal. New York, Cambridge University Press, 2006.

L'Heureux-Dubé, Claire. "The Importance of Dialogue: Globalization and the International Impact of the Rehnquist Court», en: 34 Tulsa Law Journal 15, 1998.

Landau, David. Beyond Judicial Independence: The Construction of Judicial Power in Colombia. Ph. D. Dissertation. Department of Government, Harvard University, Cambridge, 2004.

- «Political Institutions and Judicial Role in Comparative Constitutional Law», en: Harvard International Law Journal. Vol. 51, n. ${ }^{\circ}$ 2, 2010.

LAw, David. «Generic Constitutional Law», en: 89 Minnesota Law Review 652, 2005.

- «Globalization and the future of Constitutional Rights», en: Nortbwestern University Law Review, Vol. 102, n. ${ }^{\circ}$ 3, 2008.

López Medina, Diego. «El nacimiento del derecho comparado moderno como espacio geográfico y como disciplina», en: 26 International Law. Revista Colombiana de Derecho Internacional, 2015. 
Morales Antoniazzi, Mariela. «El Estado abierto como objetivo del Ius constitutionale commune», en: Armin von Bogdandy - Héctor Fix Fierro - Mariela Morales (coords.), Ius Constitutionale Commune en América Latina: rasgos, potencialidades y desafíos. México D. F.: UNAM-IIJ - Instituto Max Planck de Derecho Público, Comparado y Derecho Internacional, 2014.

Noguera Fernández, Albert - Marcos Criado de Diego, «La Constitución colombiana de 1991 como punto de inicio del nuevo constitucionalismo en América Latina», en: Estudios Socio-Jurídicos, Vol. 13, n. ${ }^{\circ}$ 1, enero-junio, 2011.

Post, Robert. «The Challenge of Globalization to American Public Law Scholarship», en: 2 Theoretical Inquiries in Law. 323, 2001.

Post, Robert - Siegel, Reva. Constitucionalismo democrático (Leonardo García J., ed. y trad.). Buenos Aires: Siglo Xxi, 2013.

Rosenfeld, Michel - Sajó, András (eds.), The Oxford Handbook of Comparative Constitutional Law. Oxford University Press, 2012, «Introduction».

Salazar Ugarte, Pedro. "La disputa por los derechos y el ius constitutionale commune», en: Armin von Bogdandy - Héctor Fix Fierro - Mariela Morales (coords.), Ius Constitutionale Commune en América Latina: rasgos, potencialidades y desafíos. México D. F.: UNAM-IIJ - Instituto Max Planck de Derecho Público, Comparado y Derecho Internacional, 2014.

Schmidhauser, John R. (ed.), Comparative Judicial Systems. Challenging Frontiers in Conceptual and Empirical Analysis. Boston: Butterworths - International Political Science Association, 1987.

Sieckmann, Jan - Clérico, Laura (eds.), Internacionalización del Derecho Constitucional. Constitucionalización del Derecho Internacional, Buenos Aires: Fundación Alexander von Humboldt - EUDEBA, 2012.

Schmidhauser, John R. (ed.), Comparative Judicial Systems. Challenging Frontiers in Conceptual and Empirical Analysis. London: Butterworths, 1987.

Slaughter, Anne-Marie. "Judicial Globalization», en: 40 Virginia Journal of International Law 1103, 2000.

- A New World Order. Princeton University Press, 2004.

Somek, Alexander. «The Deadweight of Formulae: What Might Have Been the Second Germanization of American Equal Protection Review», en: 1 University of Pennsylvania Journal of Constitutional Law, 284, 1998.

Steger, Manfred B. Globalization: A Very Short Introduction. Oxford University Press, 2003.

Tushnet, Mark. The New Constitutional Order. Princeton University Press, 2003.

TwINING, William. General Jurisprudence. Understanding Law from a Global Perspective. Cambridge University Press, 2009. 
Title:

Challenges in «Inter-Americanization» Law: The contribution of the Ius Constitutionale Commune.

\title{
Summary:
}

Introduction. I. «Inter-americanization» as epiphenomenon of the globalization of the law. II. Factual and legal realities related that reinforce the comparativism. III. The Ius Constitutionale Commune and the inter-americanizacion of the law. IV. The cannons in the Constitutional Law: what are and how transform them. V. By way of conclusion. References.

\section{Resumen:}

Este trabajo analiza algunas particularidades del proceso de globalización del derecho en el contexto latinoamericano, por cuyas especificidades resulta útil el concepto «interamericanización». Si bien los países de la región han tenido históricamente, al crear e interpretar derecho, fronteras fracturadas y relativas, desde hace algunas décadas se ha venido modificando el diálogo entre países, fundamentalmente, exportadores de reglas, principios y ciencia jurídica (el llamado norte global) y países receptores (el llamado sur global). En la actualidad la interacción se ha vuelto también horizontal entre los países del sur global que, a partir de elementos teóricos y judiciales de los cánones creados en el norte global, han construido un diálogo propio. El Ius Constitutionale Commune es la concepción jurídica que mayor potencial tiene en la región actualmente para comprender la interamericanización del derecho y analizar una de sus características más desafiantes, como es la posibilidad de transformación social desde el constitucionalismo.

\begin{abstract}
:
This article analyzes some key particularities of the process of the globalization of law in Latin America and we will be referring to the concept of «inter-americanization» in order to understand these particularities. Within the construction and development of law, the countries of this region have historically had fractured and relative frontiers. However, for some decades the institutional dialogue among exporter countries (the so-called global north) and recipient countries (the so-called global south) of rules, along with certain principles and juridical science have been dramatically changing. $\mathrm{Cu}-$ rrently, interactions have also become horizontal among global south
\end{abstract}


countries that have built their own dialogue from theoretical, judicial and doctrinary elements from the global north canon. Ius Constitutionale Commune is the legal conception with the greatest ability to understand the interamericanization of law in the region and analyze one of its most challenging characteristics, among them the possibility of social transformation from constitutionalism.

\section{Palabras clave:}

Globalización del derecho, derecho constitucional latinoamericano, cánones jurídicos, comparativismo.

\section{Key words:}

Globalization of law, Latin-American Constitutionalism, legal canons, comparativism. 

